\title{
Computer measurement of the friction of thin metal structure created in PVD technology on the flexible substrate
}

\author{
Ewa Korzeniewska ${ }^{1, *}$, Artur Szczęsny ${ }^{1}$, Jerzy Józwik ${ }^{2}$, and Arkadiusz Tofil ${ }^{3}$ \\ ${ }^{1}$ Institute of Electrical Engineering Systems, Faculty of Electrical Engineering, Electronics, Informatics and Automatic Control, Lodz \\ University of Technology, Stefanowskiego 18/22, 90-924 Łódź, Poland \\ ${ }^{2}$ Department of Production Engineering, Lublin University of Technology, Mechanical Engineering Faculty, Nadbystrzycka 36, \\ 20-816 Lublin, Poland \\ ${ }^{3}$ The Institute of Technical Sciences and Aviation, The State School of Higher Education, Pocztowa Street 54, 22-100 Chelm, Poland
}

\begin{abstract}
The paper presents the results of research study on the phenomenon of friction of thin film electroconductive structure created on composite flexible substrate and results of measurement of the friction coefficient. Tribological tests were performed on T-01M tribotester. The measurement tests were conducted according to ASTM G133 standard with a minimum force of $1 \mathrm{~N}$. A ball-on-disc friction combination was used. The study was conducted at a fixed temperature of $28^{\circ} \mathrm{C}$. Due to the nature of the tested samples, non-standard test parameters were used: test time $100 \mathrm{~s}$, data acquisition frequency $10 \mathrm{~Hz}$, slip velocity of the friction node $0.3 \mathrm{~m} / \mathrm{s}$ on a radius of $11 \mathrm{~mm}$. Based on the obtained results, the friction coefficient of the thin metallic layer $\mathrm{Ag}$ and $\mathrm{Cu}$ was determined. The obtained mean friction coefficient for a silver layer was 0.59 , while for a thin copper layer 0.67 . The knowledge of the determined coefficients will allow for effective and optimal use of the textronics materials tested in practical applications. The research methodology does not support determining the usage of the ball-on-disc pair.
\end{abstract}

\section{Introduction}

Textronics is a synergistic combination of three areas of science such as textile, electronics and computer science. Textronic structures in the form of thin electroconductive layers are exposed to the friction process and phenomena. This is due to the usage and application of textiles, among others, as clothing used in the army, fire service, police sports, sport clothing, occupational health and safety as well as medical and recreational clothing [1-5]. As a result of interactions between neighbouring materials, friction nodes are formed and created thin metal layers are subjected to abrasion, both under the influence of contact as well as the loads of these contact points, with varying forces with different dynamics. Textile materials with thin electroconductive layers created on them, used in medicine and as sports clothing, are also specific sensors that are used to control temperature and other vital parameters. The dynamic properties of the sensors used in wearable electronics depend mainly on its mechanical part [6]. Knowing the coefficient of friction will allow to determine the mechanical properties of such sensors. During medical monitoring, textronic structures exposed to friction, change the metrological properties which are important for proper working as sensors. This is extremely important because the change in their crosssection influences the characteristics of electrical parameters of specialised electroconducting textronic materials. In addition, the geometric structure of the surface layers of such materials is extremely important. The loss of material which occurs as a result of abrasion is a very important problem and it is important to be able to optimise the construction of sensory conductive elements. The change in the cross-section influences significantly the conductivity and metrological features.

Knowledge of the abrasion and wear-up mechanisms of this type of materials will allow to optimise the thickness of the deposited layers and at the same time improve the metrological parameters of the sensors made of them. The problem is so complex that the substrate used for a thin metal layer deposited in PVD process is a composite material, which is susceptible and highly deformable, which further hinders the process of controlling, monitoring and tracking changes in the thickness of applied electroconductive layers. According to the ID Tech Exhibition Report from 2016, the Compound Annual Growth Rate (CAGR), for the years from 2015 to 2018 , will be $146 \%$ for sportswear and $585 \%$ for devices using AR \& VR technology (Augmented and Virtual Reality) [7]. Textronic structures therefore play an important role and they are the basis for the implementation of sensors for end-user of devices in army or in security systems or to measure some adequate factors and provide information about vital functions. The usage of textronics electrodes to monitor patients is extremely helpful in treatment. However, it does pose engineering problems to the processing of large amounts of data. Textronic structures

\footnotetext{
* Corresponding author: ewa.korzeniewska@p.lodz.pl
} 
can also be of great use in the technical diagnostics of complex mass-dissipative-elastic systems, as well as other metallic materials and composites. They can play an important role in surface engineering. Textronic devices and systems are becoming more and more miniaturised and more flexible at the same time. Most human activities are subject to optimisation. It seeks to achieve the best product from a specific point of view. Various techniques and methods of optimisation are used for this purpose $[8,9]$. Creation of textural structures requires the usage of textile substrates, elements of miniaturised consumer electronics and the creation of components which will play the role of conductive paths. In the textronic structure it is important to produce thin metallic layers characterised by a small surface resistance value expressed in $\Omega /$ sq. One of the important properties of textronics materials is high quality of the produced layers and their resistance to mechanical factors, such as stretching or friction [10]. In many cases, the textronics systems are made in a way and on substrates that do not provide sufficient strength. The abrasiveness of the unshielded metallic coating prevents the maintenance of the electrical parameters of the used materials. Knowing the values of friction coefficient for metallic layers will allow to determine the resistance of structures made to abrasive loads.

In the literature there are results of studies related to determining the friction coefficient for thin layers in the case of metallic coatings applied to metal or ceramic elements that are part of devices used in mechanical cutting [11]. However, there are no test results for friction coefficients of metallic layers on elastic substrates used in textronics or wearable electronics. The purpose of the presented work is to supplement knowledge in this area.

\section{Subject and methods}

There are a lot of ways of creating thin films. The ion beam assisted deposition (IBAD) [12], plasma-enhanced chemical vapour deposition (PECVD) [13], deposition in sputtering procedures [14], ink-jet printing technology [15] are among them. The article presents the results of research on the friction phenomenon of metallic layers produced in the process of physical vacuum deposition (PVD) [16]. Cordura was selected as the substrate for the deposited samples of the metallic layers. Cordura is a material with high resistance to mechanical damage and also with high resistance to atmospheric conditions. The structure of its nylon fibres and the weaving method ensure its high abrasion and rubbing resistance. Because of the polyurethane top layer, low surface mass and high strength, it is widely used in the production of tourist rucksacks, expedition and cycling backpacks, as well as shoes and motorbike wear.

Electroconductive elements of textronics structures made of silver $99.99 \%$ purity and copper $99 \%$ purity were tested. Samples were created using vacuum technology PVD in the vacuum chamber of the Classic 250 Pfeiffer Vacuum system. The process of creating the structures lasted 5 minutes after reaching the $5^{*} 10^{-4} \mathrm{~Pa}$ pre-vacuum. Substrates (Cordura - flexible composite material) were cleaned on surface from contamination by mechanical rubbing with a soft cotton cloth soaked with $98 \%$ isopropyl alcohol. The thickness of the applied metallic layer is $300 \mathrm{~nm}$ on average. Surface morphology can be changed according to the factors of manufacturing processes [17-21].

Tribological tests were performed on $\mathrm{T}-01 \mathrm{M}$ tribotester (Fig. 1). The tests were conducted according to ASTM G133 standard. A ball-on-disc friction combination was used as in $[22,23]$. As co-specimen in the friction-junction the pure thin silver layer and cooper layer as well as the $\mathrm{Al}_{2} \mathrm{O}_{3}$ ball were used. The diameter of $\mathrm{Al}_{2} \mathrm{O}_{3}$ ball was $10 \mathrm{~mm}$. Samples with thin silver and copper layers were cut and glued to steel discs with a diameter of $50 \mathrm{~mm}$ and a height of $10 \mathrm{~mm}$. During the tribological tests a force of $1 \mathrm{~N}$ was applied. All processes were controlled with computer system. The tests were carried out with a sliding velocity of $0.3 \mathrm{~m} / \mathrm{s}$ friction at $11 \mathrm{~mm}$ radius and the results were recorded via dedicated software. Total test time was $100 \mathrm{~s}$. Measurements were conducted at room temperature $\left(28^{\circ} \mathrm{C}\right)$ without lubricant. The data collection rate was $10 \mathrm{~Hz}$. Friction coefficients were recorded. In order to evaluate the microstructure and mechanism of the samples surface wear down, an optical measuring instrument called 3D InfiniteFocus G5 of Alicona was used.

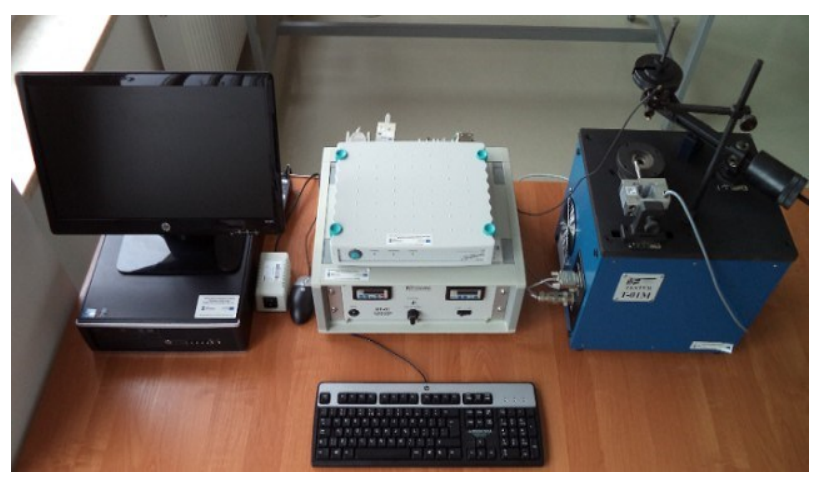

Fig. 1. View of the measurement stand: Tribtester T-01M used to measure abrasiveness.

\section{Results}

The high mean friction coefficients were recorded. During the tests, the average friction coefficient for silver thin film was equal 0.59 . On the other hand, the average friction coefficient for a thin copper layer was 0.67 .

Figure 2 shows the value of average friction coefficient for silver and copper thin films obtained during measurement.

Figure 3 shows a view of the friction surface with visible friction paths, both on specimens made of silver (Fig.3a) and copper (Fig. 3b). 


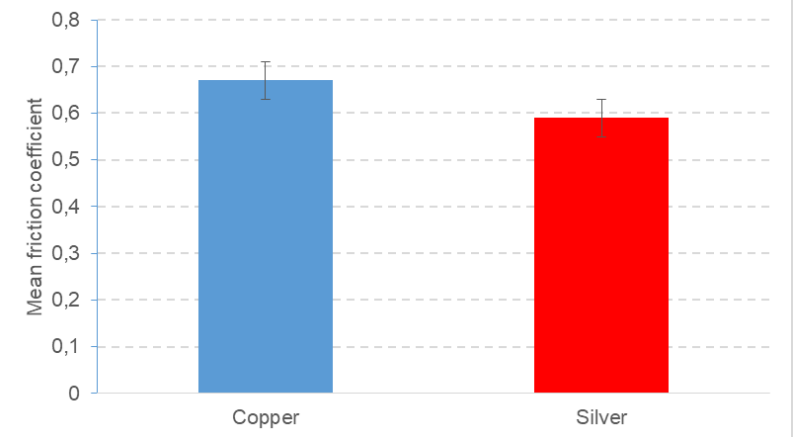

Fig. 2. The average value of measured friction coefficient.
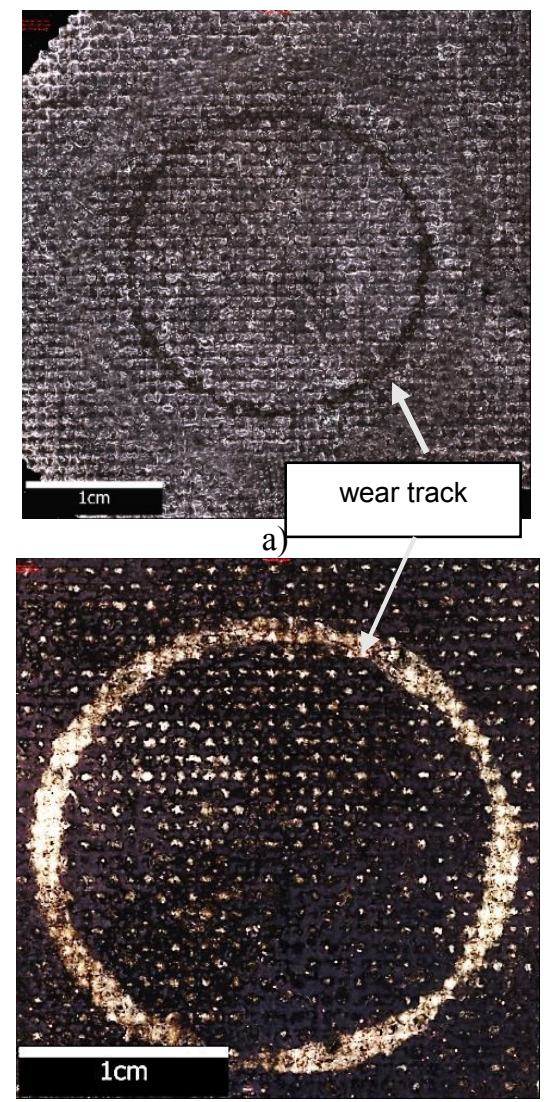

b)

Fig. 3. Friction samples with visible friction paths: a) friction trace on samples made of silver created during measurement, b) friction trace on samples made of copper created during measurement.

During the tribological tests, changes in the coefficient were recorded, what is presented in Fig. 4. It shows changes in friction coefficient at $1 \mathrm{~N}$ force recorded within $100 \mathrm{~s}$. Although high dissipation which can be seen in Fig. 4 the average friction coefficients are stable during the measurement process. It confirms the good adhesion of the created layers to the substrate. It can be seen that in the case of thin metal layers created on the composite substrate, the coefficient of friction for the pair $\mathrm{Al}_{2} \mathrm{O}_{3}$ - copper is higher than for the pair $\mathrm{Al}_{2} \mathrm{O}_{3}$ silver. The result of the measurement can be affected either by the type of material from which the friction surfaces are made, the thickness of the layers, their abrasion or the structure of the composite substrate.

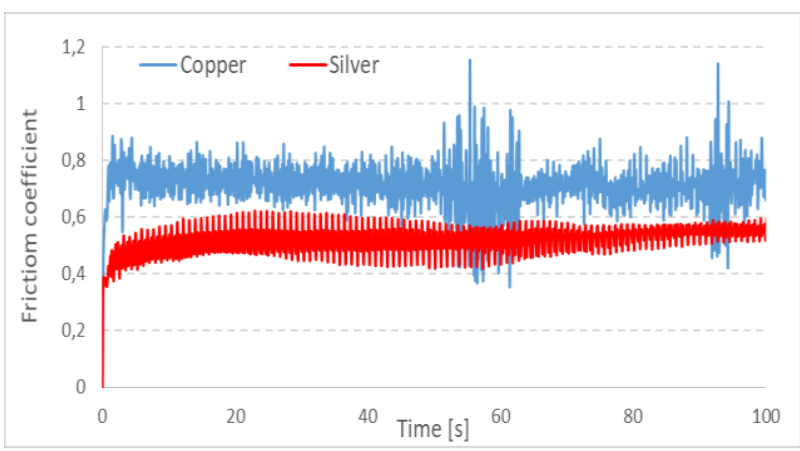

Fig. 4. Changes in measured friction coefficient.

The material layer for both silver and copper was quickly worn out and removed from the friction trace. Material transfer was being observed during friction. During the friction process of the metallic shell structure was disturbed both for silver and copper samples as the result of the friction pair damage. During friction the damages of created structures appear. They can be observed from the beginning of the process using thermography and tomography [24-26].

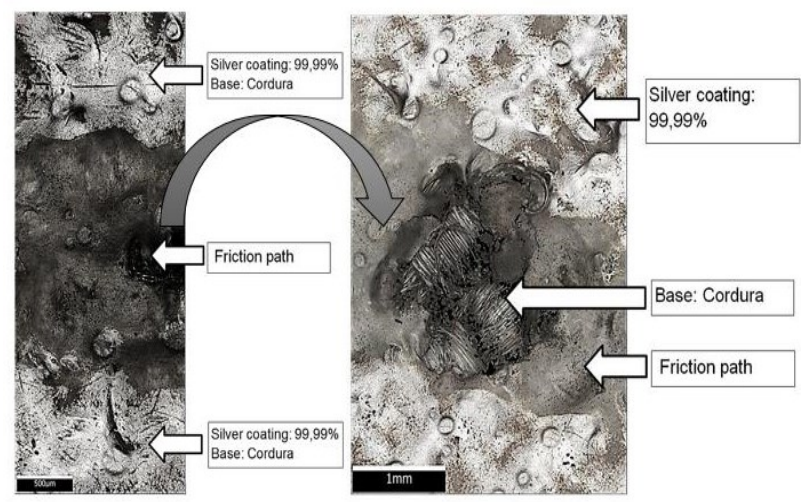

a)

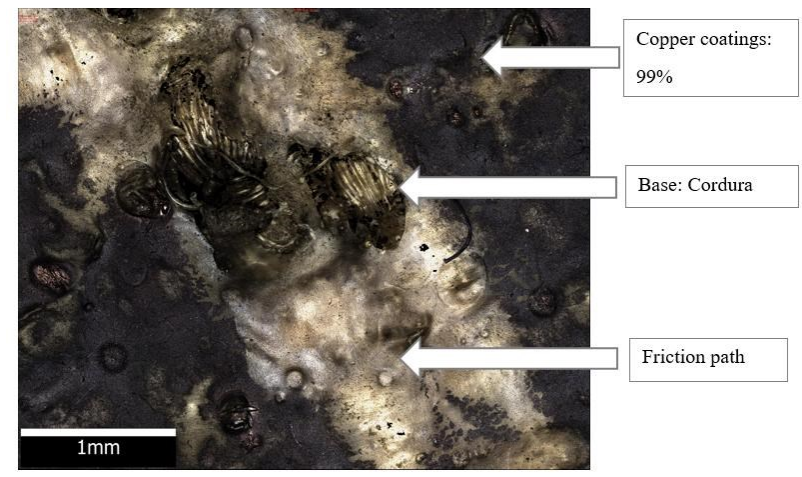

b)

Fig. 5. The view of the friction path and interruption of the metallic layer a) silver b) copper.

The view of the friction path and interruption of the metallic layer is shown in Fig. 5. In practical applications where the coating material can be subjected to intense abrasion, a thin-layer protective method should be developed. These protections will prevent elements from being destroyed and extend the life of the entire textronics structure. 


\section{Discussion}

The obtained results of friction coefficient for created metallic $\mathrm{Ag}$ and $\mathrm{Cu}$ layers is comparable to another thin layers obtained on e.g. ceramics [11]. It should be noted that for the ball-on-disc friction pair composed of 1) the tested surface of the electroconductive textronics structure with a copper layer on Cordura material and 2) the ball made of $\mathrm{Al}_{2} \mathrm{O}_{3}$ of $10 \mathrm{~mm}$ diameter, a significantly higher friction coefficient, than for the silver layer tested in these same friction conditions was obtained. Evaluation of tribological studies reveals that unprotected metallic coatings are subjected to a dynamic destroying process. It leads to the destruction of the substrate material and violates the structure of the fibres, which can eventually lead to complete destruction of the textronics elements. Despite the obtained high friction coefficient values, low strength of the coating material, its structure and the structure of the substrate on which it is deposited, as well as high temperature of the friction pair and high susceptibility to deformation make the textronics elements susceptible to friction phenomenon and rapidly deteriorate under friction conditions.

\section{Conclusion}

Basing on the measurement results, it can be stated that the value of friction coefficient of metallic conductive elements of textronics structures made in PVD process is high and it equals appropriate: for silver 0.59 and for copper 0.67 . Determining the values of these coefficients indicates the susceptibility of the layers to mechanical damage, as well as the ability to determine how to protect these structures from environmental conditions.

\section{References}

1. G.F. Eichinger; K. Baumann; T. Martin; M. Jones Proceedings of the 11th IEEE International Symposium on Wearable Computers 11-13 (2007)

2. T. Linz, L. Gourmelon, G. Langereis International Workshop on Wearable and Implantable Body Sensor Networks (BSN 2007), 29-34 (2007)

3. C. JaeHan, Y. Kim, K. Lee, Y.C. Chung IEEE Antennas and Propagation Society International Symposium 5-11 (2008)

4. T. Xuyuan, K. Vladan, H. Tzu-Hao, S. Chien-Lung, K. Ya-Chi, J. Gwo-Tsuen Sensors 17, 673 (2017)

5. A. Jakubas, E. Lada-Tondyra The Journal of The Textile Institute (2018) doi.org/10.1080/00405000.2017.1422308

6. J. Zięba, M. Frydrysiak, K. Gniotek FIBRES \& TEXTILES in Eastern Europe 15(5) 64 - 65(2007)

7. X. Tao, V. Koncar, T.H. Huang, C.L. Shen, Y.C. Ko, G.T. Jou: Sensors (Basel) 17(4): 673 (2017).
8. L. Kasprzyk, A. Tomczewski, K. Bednarek Przeglad Elektrotechniczny 87(12) 82-85 (2011)

9. L. Kasprzyk, K. Bednarek Przeglad Elektrotechniczny 85(12) 65-68 (2009)

10. E. Korzeniewska, M. Walczak, J. Rymaszewski MIXDES - 24th International Conference "Mixed Design of Integrated Circuits and Systems 447 450, article number 8005250 (2017)

11. B. Warcholiński, A. Gilewicz, P. Myśliński Reviews on Advanced Materials Science. 22(2009) 81-88

12. X. Li, W. Yue, C. Wang, J. Liu, G. Li Journal of Tribology 139 (6) (2017)

13. N. W. Khun, A. Neville, I. Kolev, H. Zhao Journal of Tribology 138 (3) doi: 10.1115/1.4031995 (2016)

14. J. Jozwik, L. Semotiuk, I. Kuric, Adv. Sci. Technol. Res. J. 2015; 9(28):96-102

15. R. Pawlak, E. Korzeniewska, Z. Stempien, Selected Issues of Electrical Engineering and Electronics, WZEE 2016, 7800248 (2016)

16. E. Korzeniewska, J. Józwik, R. Zawiślak, A. Krawczyk, J. Michałowska Przeglad Elektrotechniczny 12(93) 111-114 (2017)

17. M. Barszcz, J. Józwik, K. Dziedzic, K. Stec. E3S WEB OF CONFERENCES. 2017, vol. 19, s. 1-6

18. G. M. Krolczyk, J. B. Krolczyk, R. W. Maruda, S. Legutko, M. Tomaszewski Measurement 88 176185 (2016)

19. R. Pawlak, M. Lebioda, J. Rymaszewski, W. Szymanski, L. Kołodzieczyk, P. Kula, Sensors 17(1) article number: 51 (2017)

20. Jozwik, Jerzy; Czwarnowski, Marek : Adv. Sci. Technol. Res. J. 2015; 9(28):89-95,

21. G. M. Krolczyk, P. Nieslony, R. W. Maruda, S. Wojciechowski Journal of Cleaner Production 142 3343-3354 (2017)

22. J. Jozwik: Tehnicki Vjesnik - Technical Gazette. 2018, nr 25, Supl.1, s. 170-175

23. M. Pashechko, K. Dziedzic, E. Mendyk, J. Jozwik Journal of Tribology 140 (2) (2017) doi: 10.1115/1.4037953

24. T. Światczak, M. Tomczyk, B. Więcek, R. Pawlak, R. Olbrycht Materials Science and Engineering B: Solid-State Materials for Advanced Technology 177 (15) 1239-1242 (2012)

25. T. Rymarczyk; P. Adamkiewicz, J. Sikora, Przeglad elektrotechniczny, 94 (1), 93-96 (2018).

26. T. Rymarczyk; J. Szumowski, P. Adamkiewicz, P. Tchórzewski, J. Sikora, Przeglad elektrotechniczny, 94 (1) 97-100 (2018). 